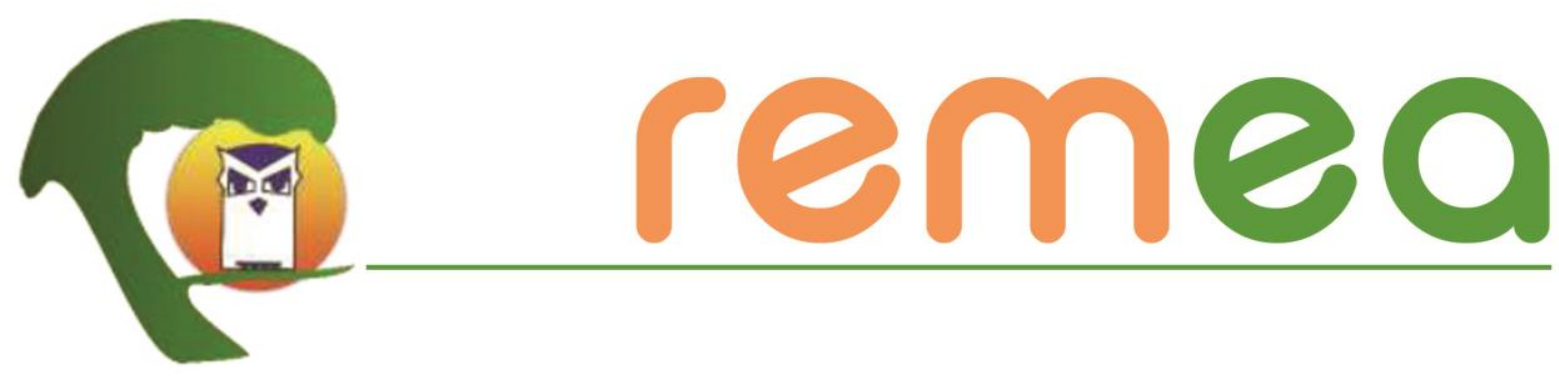

\title{
O perfil institucional da educação ambiental no ensino médio profissional do município de Juazeiro do Norte, Ceará
}

\author{
Janiele de Brito de Souza ${ }^{1}$ \\ Universidade Federal do Cariri \\ ORCID: https://orcid.org/0000-0002-4712-329X \\ Marcelo Martins de Moura-Fé2 \\ Universidade Regional do Cariri \\ ORCID: https://orcid.org/0000-0002-0336-557X \\ Marcus Vinicius de Oliveira Brasil $\left.\right|^{3}$ \\ Universidade Federal do Cariri \\ ORCID: https://orcid.org/0000-0001-6525-9257
}

RESUMO: A legislação nacional defende uma Educação Ambiental (EA) curricular integrada e transversal em todos os níveis e modalidades de ensino; sendo essas ações um pressuposto para a construção de sociedades sustentáveis. Por isso, o objetivo central desse trabalho é verificar o perfil institucional da EA no ensino médio profissional do município de Juazeiro do Norte, Ceará. Metodologicamente, foi realizada uma criteriosa revisão de literatura e documental; assentando-se no método dedutivo e qualitativo, com objetivo exploratório e descritivo; foi realizada ainda uma "entrevista por pauta" com a gestão da escola, objeto do estudo de caso. Como resultado, a pesquisa aponta para a inserção multi e interdisciplinar da EA na Educação Profissional Técnica (EPT) de nível médio do município, em confluência com as dimensões da sustentabilidade de Sachs (2002).

Palavras-chave: Contexto da Educação. Indicadores de Educação Ambiental. Práticas de Educação Ambiental.

\section{El perfil institucional de la educación ambiental en el bachillerato profesional de la ciudad de Juazeiro do Norte, Ceará}

\footnotetext{
1 Economista. Mestra em Desenvolvimento Regional Sustentável (UFCA). Professora substituta do Centro de Ciências Sociais Aplicadas (CCSA-UFCA). E-mail: janiele.brito@gmail.com

2 Geógrafo. Doutor em Geografia (PPGG-UFC). Professor da Universidade Regional do Cariri (URCA). Professor do Proder (UFCA). E-mail: marcelo.mourafe@urca.br

3 Doutor em Administração de Empresas. Professor da UFCA e do Proder (UFCA). E-mail: marcus.brasil@ufca.edu.br
} 
RESUMEN: La legislación nacional defiende una Educación Ambiental (EA) curricular integrada y transversal en todos los niveles y modos de educación; estas acciones son un requisito previo para la construcción de sociedades sostenibles. Por esta razón, el objetivo principal de este trabajo es verificar el perfil institucional de la EA en el bachillerato profesional de la ciudad de Juazeiro do Norte, Ceará. Metodológicamente, se llevó a cabo una revisión exhaustiva de literatura y documentos; basado en el método deductivo y cualitativo, con un objetivo exploratorio y descriptivo; También se realizó una "entrevista por agenda" con la dirección de la escuela, objeto del estudio de caso. Como resultado, la investigación apunta a la inserción multi e interdisciplinar de la EA en la Educación Técnica Vocacional (EPT) de nivel medio en el municipio, en confluencia con las dimensiones de sustentabilidad de Sachs (2002).

Palabras clave: Contexto educativo. Indicadores de educación ambiental. Prácticas de educación ambiental.

\section{The institutional profile of environmental education in professional high school of Juazeiro do Norte, Ceará}

ABSTRACT: National legislation defends an integrated and transversal curricular Environmental Education (EA) at all levels and teaching modalities; these actions being a prerequisite for building sustainable societies. For this reason, the main objective of this work is to verify the institutional profile of $A E$ in professional high school in the city of Juazeiro do Norte, Ceará. Methodologically, a thorough review of literature and documents was carried out; based on the deductive and qualitative method, with an exploratory and descriptive objective; an "interview by agenda" was also carried out with the school management, object of the case study. As a result, the research points to the multi and interdisciplinary insertion of AE in Technical Vocational Education (EPT) of medium level in the municipality, in confluence with the dimensions of sustainability by Sachs (2002).

Key-words: Education Context. Environmental Education Indicators. Environmental Education Practices.

\section{INTRODUÇÃO}

As Escolas Estaduais de Educação Profissional (EEEPs) do Estado do Ceará foram instituídas em 2008, através da Lei Estadual no 14.273 (CEARÁ, 2008), objetivando estabelecer uma política pública de educação profissional para o Estado em detrimento de sua participação no Programa Brasil Profissionalizado, criado por meio do Decreto Presidencial $\mathrm{n}^{\circ}$ 6.302/2007 (CEARÁ, 2014), cuja finalidade foi estimular a integração da educação profissional ao ensino médio, enfatizando a educação científica e humanística, e a articulação entre a escola e os arranjos produtivos locais e regionais (BRASIL, 2007a).

Baseando-se nesses pressupostos, a Coordenadoria de Educação Profissional do Ceará defende que a "política de educação profissional deve estar articulada às demais políticas social, cultural, ambiental e econômica, proporcionando tanto no âmbito local como regional um desenvolvimento integrado" (CEARÁ, 2014, p. 190). Por isso, a promoção da Educação Ambiental (EA) na Educação Profissional Técnica (EPT) de nível médio é fundamental para vincular este saber educacional à ética, ao trabalho e às práticas sociais; com vistas a 
preservação do meio ambiente e sua interdependência com o desenvolvimento socioeconômico e cultural dos territórios (BRASIL, 1999; 2012a; 2012b).

Ademais, essas instituições foram implantadas com funcionamento em tempo integral, ou seja, das 07:00 às 17:00 horas, com um total de 2.620 horas na Base Comum, complementadas pelo ensino técnico e a parte diversificada, totalizando 5.400 horas de carga horária ao final dos três anos (CEARÁ, 2014). Em virtude disso, as EEEPs detêm uma maior disponibilidade de tempo e infraestrutura necessários para uma efetiva implementação das atividades teóricas e práticas de EA no contexto escolar (escola e comunidade), além, obviamente, da formação de jovens profissionais conscientes e corresponsáveis com a preservação do meio ambiente.

Em consonância a isso, definir o perfil institucional da EA nessas instituições de ensino, implica, sobremaneira, mostrar como os gestores enxergam ("que praticam") as atividades didático-pedagógicas de EA em conexão com as dimensões da sustentabilidade (social, cultural, ambiental, territorial, econômica e política) de Sachs (2002).

Diante dessa conjectura, o objetivo aqui é verificar o perfil institucional da EA no ensino médio profissional do município de Juazeiro do Norte-CE. Como objetivos específicos, têm-se: i) conhecer as diretrizes para a EA nas Escolas Estaduais de Educação Profissional do Ceará; e, ii) identificar as ações didático-pedagógicas de EA na EEEP Raimundo Saraiva Coelho.

\section{MATERIAL E MÉTODOS}

\section{1 Área de Estudo}

O estudo em questão se aplica às Escolas Estaduais de Educação Profissional (EEEPs) de Juazeiro do Norte; município brasileiro pertencente ao Estado do Ceará, localizado na Região Metropolitana do Cariri (RMC), no sul do estado, distante 491 km da capital, Fortaleza, como mostra a Figura 1. Possui uma população estimada, para o ano de 2019, de 274.207 pessoas e área territorial de $248,832 \mathrm{~km}^{2}$ (IBGE, 2020). Se destaca como polo industrial nos ramos calçadistas, têxtil, folheados, artesanato, bebidas, máquinas, construção civil e metalurgia, além do comércio dinâmico impulsionado pelo turismo religioso (as romarias do Padre Cícero) (CASTRO et al., 2013). 
Figura 1 - Localização do município de Juazeiro do Norte na RMC

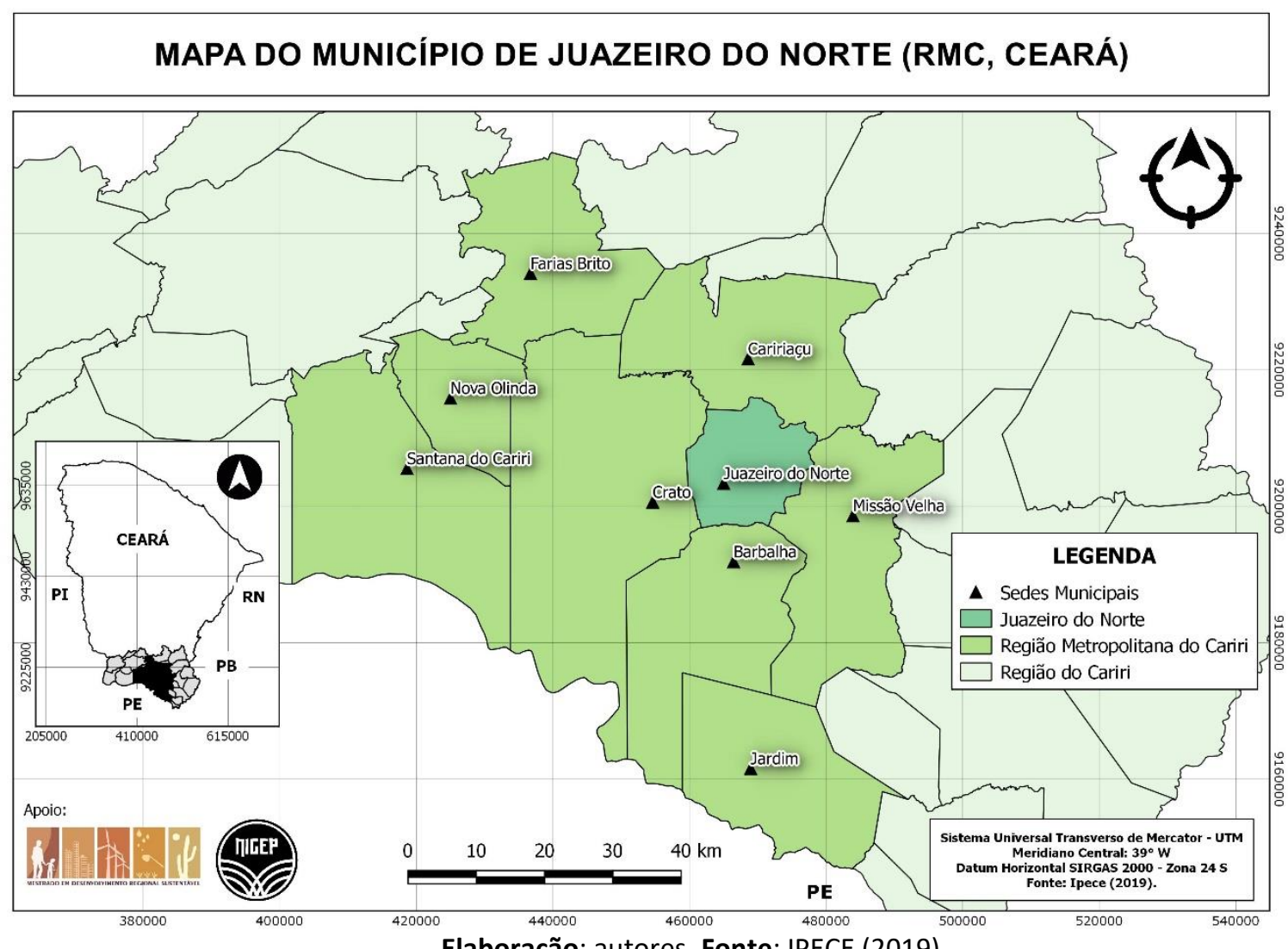

Elaboração: autores. Fonte: IPECE (2019).

\subsection{Fontes dos Dados}

O caminho para a construção da fundamentação teórica e de seus resultados se deu, inicialmente, a partir da obtenção de dados secundários, oriundos de uma criteriosa revisão bibliográfica e documental, sendo recorrente os parâmetros legais da Política Nacional de Educação Ambiental - PNEA (Lei no 9.795/1999); das Diretrizes Curriculares Nacionais para a Educação Profissional Técnica de Nível Médio (Resolução no 06/2012); além da Política Estadual de Educação Ambiental do Ceará (Lei no 14.892/2011), entre outros.

Nesta etapa foram consultados periódicos consolidados na temática da EA, disponibilizados no Google Acadêmico, SciELO e Periódicos CAPES; além de livros, sites e dados oficiais do Ministério da Educação (MEC), Sistema Nacional de Informações da Educação Profissional e Tecnológica (SisTec), Secretaria de Educação do Governo do Ceará (Seduc), Instituto Brasileiro de Geografia e Estatística (IBGE) e Instituto de Pesquisa e Estratégia Econômica do Ceará (IPECE). 
Quanto ao objeto da pesquisa, ressalta-se que o município de Juazeiro do Norte foi contemplado com três EEEPs: Aderson Borges de Carvalho, Professor Moreira de Souza e Raimundo Saraiva Coelho. Contudo, adotou-se a estratégia de pesquisa do Estudo de Caso, a ser realizado na EEEP Raimundo Saraiva Coelho (EEEP RSC), com o intuito de permitir a expansão e generalização das proposições teóricas (YIN, 2001) em torno das atividades didático-pedagógicas de EA para o ensino médio profissional do município.

Destaca-se que a coleta dos dados primários se deu através da realização de uma entrevista com a antiga4 Gestão da EEEP RSC, após o parecer favorável do Comitê de Ética em Pesquisa (CEP)5, em atendimento a Resolução no 510/2016, do Conselho Nacional de Saúde (CNS) (BRASIL, 2016); sendo a coleta conduzida através de "entrevista por pauta", que na concepção de Gil (2008) é aquela em que se permite ao entrevistado falar livremente frente as pautas assinaladas pelo pesquisador.

Vale frisar que essa entrevista foi realizada de forma virtual, pelo aplicativo Google Meet; em virtude do decreto estadual no 33.510/2020 (CEARÁ, 2020a) e suas prorrogações, no qual são reiterados o estado de calamidade pública e situação de emergência em saúde decorrentes da pandemia do novo Coronavírus (COVID-19) e a consequente suspensão das atividades educacionais presenciais em todas as escolas do Ceará.

Além disso, a elaboração dos pontos de pauta da entrevista teve como embasamento a Matriz de Indicadores de EA na escola (vide quadro 4) proposta por Vieira, Campos e Morais (2019). Esse instrumento contempla dez indicadores, organizados em três dimensões (Gestão, Currículo e Espaço Físico) e permite uma análise por indicador ou dimensão, além de interrelações entre as dimensões (VIEIRA; CAMPOS; MORAIS, 2019).

Por fim, devido a pandemia do COVID-19 não foi possível realizar visitas presenciais à escola durante a coleta dos dados primários, por isso, recorreu-se aos registros institucionais (fotos, vídeos, editais e outros documentos) presentes no blog da EEEP RSC. Para a elaboração da nuvem de palavras (vide figura 2), recorreu-se a plataforma online WordClouds.

4 Núcleo Gestor vigente até 27 de janeiro de 2020.

5 CAAE: 34076620.3.0000.5698; número do parecer: 4.179 .560

Revista Eletrônica do Mestrado em Educação Ambiental 


\subsection{Métodos de Análise}

Para que um conhecimento possa ser considerado científico, torna-se necessário definir o caminho para se chegar a determinando fim (GIL, 2008). Por isso, reitera-se que o presente estudo se assenta no método dedutivo, tendo em vista permitir o encadeamento dos princípios gerais da EA ao ensino médio profissional e, mais especificamente, contextualizá-los na EEEP RSC e demais EEEPs do município de Juazeiro do Norte.

Por outro lado, apresenta uma abordagem de pesquisa do tipo qualitativa e objetivos de natureza exploratória e descritiva. Exploratória, por proporcionar uma visão geral sobre determinado fato (GIL, 2008), neste caso, o modo como a EA se aplica, prática e teoricamente, no ensino médio integrado à educação profissional das EEEPs de Juazeiro do Norte. Descritiva, por caracterizar a EA nestas instituições e demonstrar como essa variável interferiu no "projeto de vida" dos gestores escolares, colaboradores, discentes e comunidade ao seu entorno.

Por último, decidiu-se pela expansão e generalização teórica do Estudo de Caso, que para Yin (2001, p. 32) é uma fundamentação "empírica que investiga um fenômeno contemporâneo dentro do seu contexto da vida real, especificamente quando os limites entre o fenômeno e contexto não estão claramente definidos". Neste caso, trata-se de um estudo de caso único, do tipo explicativo e descritivo (YIN, 2001).

Seguindo as orientações de Yin (2001), o protocolo definido para o estudo de caso foi: i) para se permitir uma visão geral do projeto foi feito um estudo metodológico para compreender o universo da instituição escolhida para representar as demais Escolas Profissionais do município; ii) quanto aos procedimentos de campo, foi feita uma primeira visita para observação direta da realidade institucional (antes da pandemia), seguida da entrevista com a gestão da escola; iii) em relação as questões do estudo de caso, essas tiveram como embasamento as pautas apresentadas no quadro 4; por fim, iv) a análise dos dados.

\section{FUNDAMENTAÇÃO}

Em 1991, durante a Conferência das Nações Unidas sobre Meio Ambiente e Desenvolvimento (Rio - 92), a Educação Ambiental (EA) foi reconhecida como um dos 
instrumentos da política ambiental brasileira (BRASIL, 2018a). Por essa razão, consagrou-se como uma importante aliada na construção de sociedades sustentáveis, cujo foco do ideário desenvolvimentista, baseado no crescimento econômico e expropriação exacerbada dos recursos naturais, passara a ser conduzido, na opinião de Trajber (2017), por princípios democráticos e participativos de responsabilidade global.

Com isso, o modelo de desenvolvimento sustentável, outrora discutido na Rio-92 e citado no Relatório Brundtland, em 1987, como sendo aquele capaz de satisfazer as necessidades do presente sem comprometer a capacidade de as futuras gerações satisfazerem as suas próprias necessidades (CMMAD, 1991) guiou-se, na concepção de Sachs (2002; 2008), para além da sustentabilidade ambiental, incluindo as dimensões social, cultural, territorial, econômica e política.

Deste modo, espera-se que a EA desenvolva "valores sociais, conhecimentos, habilidades, atitudes e competências voltadas para a conservação do meio ambiente, bem de uso comum do povo, essencial à sadia qualidade de vida e sua sustentabilidade" (BRASIL, 1999, art. 10); devendo, portanto, ser direcionada a todos os níveis e modalidades do processo educativo, em caráter formal e não-formal (BRASIL, 1999, art. 2ㅇ). Outrossim, a fim de estabelecer as bases para o desenvolvimento sustentável do país, é fundamental que as atividades didático-pedagógicas de EA levem em consideração todas as dimensões da sustentabilidade elencadas por Sachs (2002).

Isso é defendido, embora que nas entrelinhas, pelas Diretrizes Curriculares Nacionais para a Educação Ambiental, pois ao referenciar os principais objetivos da EA, cita, no início do art.14으, que a mesma deve contemplar:

I - Abordagem curricular que enfatize a natureza como fonte de vida e relacione a
dimensão ambiental à justiça social, aos direitos humanos, à saúde, ao trabalho, ao
consumo, à pluralidade étnica, racial, de gênero, de diversidade sexual, e à
superação do racismo e de todas as formas de discriminação e injustiça social"
(BRASIL, 2012a). Grifo nosso.

Sendo assim, observa-se que a EA, através de uma abordagem curricular integrada e transversal (BRASIL, 2012a) em todos os níveis de ensino é pressuposto para que uma sociedade alcance patamares de desenvolvimento sustentável (BARRETO; CHACON; NASCIMENTO, 2012). Ademais, o trabalho é parte integrante da EA, justificando, dessa maneira, a necessidade de desenvolvê-la no ensino médio integrado à educação profissional. 
Nas últimas duas décadas essa modalidade de ensino ganhou impulso com o Programa Brasil Profissionalizado (PBP), instituído pela União através do Decreto no 6.302/2007, cujo objetivo foi "prestar assistência financeira e ações de desenvolvimento e estruturação do ensino médio integrado à educação profissional" (BRASIL, 2007a, art.1ํ), com vistas a expandir o atendimento e melhorar a qualidade da educação brasileira; combinar formação geral, científica e cultural com a formação profissional dos discentes e; dentre outros objetivos, propiciar a articulação entre a escola e os arranjos produtivos locais e regionais (BRASIL, 2007a).

Para Viana e Castioni (2017), o PBP surgiu em um cenário de recuperação da economia brasileira, com expansão do crédito, recordes nas bolsas de valores, descoberta do pré-sal pela Petrobrás, além do lançamento do Programa de Aceleração do Crescimento (PAC), justificando numa maior demanda por mão de obra qualificada. Além disso, foi dado apoio técnico e financeiro aos estados brasileiros para a construção de escolas, ampliação, reforma, aquisição de recursos e materiais, mobiliário, equipamentos, laboratórios, livros, além da formação dos gestores e professores (LEITE; ANDRADE, 2019).

Assim, se desenhou uma política pública de educação profissional no estado do Ceará, culminando, no 20 semestre de 2008, na criação dos Centros Educacionais para a Juventude (CEJOVEM) (CEARÁ, 2014). Estes passaram a ser definidos como Escolas Estaduais de Educação Profissional (EEEP) pela Lei Estadual no 14.273/2008 (CEARÁ, 2008); sendo a Coordenadoria da Educação Profissional (COEDP), órgão vinculado à Secretaria da Educação do Ceará (Seduc), responsável pela orientação das EEEPs no processo de integração do ensino médio e educação profissional (CEARÁ, 2019a).

Neste aspecto, Leite e Andrade (2019) destacam o PBP como um verdadeiro divisor de águas em relação ao que se tinha antes e depois do Programa; corroborando, segundo Castelo Branco e Magalhães Jr. (2015) no pioneirismo do estado do Ceará quanto ao modelo apresentado e implantado, pois até àquele momento não havia no Brasil nenhuma escola estadual integral que ofertasse o ensino técnico juntamente ao ensino médio.

Vale destacar que as escolas estaduais cearenses tiveram como inspiração as escolas de período integral do estado de Pernambuco (Programa de Desenvolvimento dos Centros de Ensino Experimental - Procentro) e as escolas técnicas federais e canadenses visitadas (CASTELO BRANCO; MAGALHÃES JR., 2015). Por isso, as EEEPs do Ceará funcionam em tempo 
integral, das 7 às 17 horas, no qual são oferecidas 3 refeições diárias, fardamento, material didático, espaços pedagógicos para o melhor aprendizado e um currículo que integra a formação geral e profissional, além de outros componentes curriculares potencializadores da formação integral, humana e ética dos alunos (CEARÁ, 2014).

Para tanto, a escolha dos cursos e dos municípios estão atrelados ao projeto de desenvolvimento econômico e produtivo do Ceará (CEARÁ, 2014), constata-se, que após 10 anos de implantação das Escolas Profissionais no Estado, houve uma significativa expansão em 2018, quanto ao: número de escolas - ampliação de 25 para 119; número de municípios contemplados - ampliação de 20 para 95; número de cursos técnicos ofertados - ampliação de 4 para 52 cursos (CEARÁ, 2019a).

O Quadro 1 mostra como se deu a distribuição das Escolas Profissionais nos municípios da RMC, bem como os cursos técnicos ofertados no ano de 2020.

Quadro 1 - Escolas Estaduais de Educação Profissional na RMC, em 2020

\begin{tabular}{|c|c|c|}
\hline MUNICÍPIO & EEEP & CURSOS TÉCNICOS \\
\hline Barbalha & Otília Correia Saraiva & Enfermagem; Nutrição e Dietética; Rede de Computadores \\
\hline Caririaçu & Paulo Barbosa Leite & $\begin{array}{c}\text { Administração; Agropecuária; Redes de Computadores; } \\
\text { Informática }\end{array}$ \\
\hline \multirow{2}{*}{ Crato } & Governador Virgílio Távora & $\begin{array}{c}\text { Enfermagem; Informática; Redes de Computadores; } \\
\text { Regência }\end{array}$ \\
\hline & $\begin{array}{c}\text { Maria Violeta Arraes Alencar } \\
\text { Gervaiseau }\end{array}$ & $\begin{array}{c}\text { Estética; Manutenção Automotiva; Produção de Áudio e } \\
\text { Vídeo; Redes de Computadores }\end{array}$ \\
\hline Farias Brito & Obra em execução (23\%) & - \\
\hline Jardim & Dr. Napoleão Neves da Luz & Administração; Agropecuária; Contabilidade; Informática \\
\hline \multirow{3}{*}{$\begin{array}{l}\text { Juazeiro do } \\
\text { Norte }\end{array}$} & Aderson Borges de Carvalho & Administração; Enfermagem; Informática \\
\hline & Professor Moreira de Souza & Informática; Comércio; Hospedagem; Massoterapia \\
\hline & Raimundo Saraiva Coelho & $\begin{array}{c}\text { Agrimensura; Desenho da Construção Civil; Design de } \\
\text { Interiores; Edificações; Finanças; Meio Ambiente; } \\
\text { Transações Imobiliárias }\end{array}$ \\
\hline Missão Velha & Obra paralisada (27\%) & - \\
\hline Nova Olinda & $\begin{array}{l}\text { Wellington Belém de } \\
\text { Figueiredo }\end{array}$ & Agronegócio; Edificações; Finanças; Informática \\
\hline $\begin{array}{l}\text { Santana do } \\
\text { Cariri }\end{array}$ & - & - \\
\hline
\end{tabular}

Elaboração: autores. Fonte: BRASIL (2020a; 2020b; 2020c); CEARÁ (2019a; 2020b; 2020c).

Para Nascimento et al. (2013) as desigualdades inter-regionais entre as microrregiões cearenses são ainda bastante evidentes. No caso da RMC, os municípios de Barbalha, Crato e 
Juazeiro do Norte concentram os maiores índices populacionais e os melhores indicadores socioeconômicos regionais (Tabela 1), tendo em vista agregarem economias de polo industrial, comercial e de serviços (MORAES; MACEDO, 2014).

Tabela 1 - Indicadores Socioeconômicos dos municípios da RMC

\begin{tabular}{lcccc}
\hline Município & $\begin{array}{c}\text { População } \\
\text { Estimada }\end{array}$ & $\begin{array}{c}\text { PIB } \\
\text { (Preços correntes - } \\
\text { R\$ 1.000) } \\
\mathbf{( 2 0 1 6 )}\end{array}$ & $\begin{array}{c}\text { Empregos } \\
\text { Formais }\end{array}$ & $\begin{array}{c}\text { Consumo de energia } \\
\text { elétrica (mwh) }\end{array}$ \\
\hline Barbalha & $\mathbf{( 2 0 1 8 )}$ & $\mathbf{( 2 0 1 7 )}$ & $\mathbf{( 2 0 1 7 )}$ \\
Caririaçu & 60.155 & 175.920 & 9.708 & 82.569 \\
Crato & 27.095 & 177.042 & 1.797 & 15.198 \\
Farias Brito & 131.372 & 1.509 .564 & 18.084 & 131.594 \\
Jardim & 18.882 & 130.207 & 1.161 & 11.644 \\
Juazeiro do Norte & 27.284 & 178.099 & 1.681 & 12.490 \\
Missão Velha & 35.662 & 4.185 .792 & 48.843 & 332.989 \\
Nova Olinda & 15.520 & 330.368 & 3.025 & 37.744 \\
Santana do Cariri & 17.622 & 117.890 & 1.413 & 12.472 \\
\hline
\end{tabular}

Elaboração: autores. Fonte: Adaptado de IPECE (2018).

De antemão, reforça-se aqui a não pretensão em aprofundar a natureza dos respectivos indicadores, até porque não é objetivo deste estudo. Portanto, o que se pretende é associar a escolha dos municípios (vide quadro 1) para a destinação dos recursos públicos e a consequente instalação das EEEPs na RMC aos seus respectivos indicadores socioeconômicos (ver tabela 1). Dessa maneira, percebe-se, nitidamente, que as três maiores cidades (Barbalha, Crato e Juazeiro do Norte) figuram como as mais populosas; com maior nível de atividade econômica (PIB), maior consumo de energia elétrica; e, por conseguinte, maior número de empregos formais; justificando o quantitativo de 06 EEEPs, dentre um total de 09 EEEPs ativas em toda a RMC.

Como justificativa, Aguiar Neto e Teixeira (2012) explicam que o conjunto formado por essas metrópoles regionais, denominada de Crajubar (Crato - Juazeiro do Norte Barbalha) têm impulsionado o desenvolvimento da RMC e atraído muitas empresas. Não obstante, os outros municípios da RMC, por representarem uma importância econômica reduzida frente aos demais (MORAES; MACEDO, 2014) foram contemplados com apenas 01 
EEEP; com exceção de Santana do Cariri, que não possui EEEP instalada ou em fase de construção/adaptação, pois dentre todos os municípios da RMC, é o que apresenta o pior cenário econômico e social, ainda conforme a tabela 1.

Por fim, reforça-se aqui a capacidade da educação (neste caso, na modalidade profissional) em disseminar valores e conhecimentos para a construção do ambiente propício à consecução de um desenvolvimento comprometido com o bem-estar coletivo (BARRETO; CHACON; NASCIMENTO, 2012) e ambientalmente sustentável. Além do mais, "é pelo trabalho que os seres humanos produzem conhecimento, desenvolvem concepções de mundo, viabilizam a convivência, transformam a natureza, organizam-se socialmente e fazem história" (CEARÁ, 2014, p. 115).

\section{RESULTADOS E DISCUSSÃO}

\subsection{Diretrizes para a EA nas Escolas Estaduais de Educação Profissional do Ceará}

A institucionalização da PNEA e das Diretrizes Curriculares Nacionais para a educação ambiental (BRASIL, 1999; 2012a) foram essenciais para a construção e disseminação das ações de EA no Brasil. A partir disso, sua inserção obrigatória nos currículos da Educação Básica e Educação Superior se deu pela transversalidade, devendo esta relacionar-se às temáticas que envolvam a sustentabilidade socioambiental; aos componentes já constantes do currículo; ou pela combinação de ambos (BRASIL, 2012a).

Consoante a isso, cabe aos Estados, o Distrito Federal e aos Municípios definirem suas diretrizes, normas e critérios para a EA em suas respectivas áreas de jurisdição (BRASIL, 1999). Dessa maneira, o Ceará instituiu, a partir da Lei no 14.892/2011, a Política Estadual de Educação Ambiental (CEARÁ, 2011); que, dentre outras coisas, reforça a determinação da PNEA sobre a obrigatoriedade da EA no ensino formal e não-formal (BRASIL, 1999).

A partir disso, Juazeiro do Norte estabeleceu a Política Municipal do Meio Ambiente (Lei no 3851/2011) com foco na preservação, melhoria e recuperação da qualidade ambiental; e, entre os princípios norteadores, destaca a promoção da EA e a necessidade de empreender ações de EA integradas ao programa de conservação, recuperação e melhoria do meio 
ambiente, além do estímulo às práticas culturais, hábitos, costumes e atividades socioeconômicas não prejudiciais ao meio ambiente (JUAZEIRO DO NORTE, 2011).

Conquanto, o fato é que os projetos institucionais e pedagógicos da Educação Básica devem propor ações educativas, de organização e de gestão curricular que integrem o papel socioeducativo, ambiental, artístico, cultural e as questões de gênero, etnia, raça e diversidade (BRASIL, 1999). Para Brasil (2012b), isso implica aos cursos da EPT de nível médio vincularem os conhecimentos da Educação Básica, indispensáveis para a formação e desenvolvimento profissional do aluno, aos fundamentos científicos, sociais, organizacionais, econômicos, políticos, culturais, ambientais, estéticos e éticos.

São também princípios do Ensino Médio, de uma maneira geral:

I - formação integral do estudante, expressa por valores, aspectos físicos, cognitivos e socioemocionais;

II - projeto de vida como estratégia de reflexão sobre trajetória escolar na construção das dimensões pessoal, cidadã e profissional do estudante;

III - pesquisa como prática pedagógica para inovação, criação e construção de novos conhecimentos;

IV - respeito aos direitos humanos como direito universal;

V - compreensão da diversidade e realidade dos sujeitos, das formas de produção e de trabalho e das culturas;

$\mathrm{VI}$ - sustentabilidade ambiental;

VII - diversificação da oferta de forma a possibilitar múltiplas trajetórias por parte dos estudantes e a articulação dos saberes com o contexto histórico, econômico, social, científico, ambiental, cultural local e do mundo do trabalho;

VIII - indissociabilidade entre educação e prática social, considerando-se a historicidade dos conhecimentos e dos protagonistas do processo educativo;

IX - indissociabilidade entre teoria e prática no processo de ensino-aprendizagem (BRASIL, 2018b, art. 5ㅇ). Grifo nosso.

Nesse contexto, pode-se afirmar que as ações de EA previstas pela legislação nacional, estadual e municipal, corroboram com a obrigatoriedade de sua inserção na Educação Básica; consubstanciando, portanto, no dever legal das Escolas Profissionais do Ceará de inserirem e promoverem ações interdisciplinares de EA através dos Regimentos Escolares, Planos Políticos Pedagógicos (PPP); Matrizes Curriculares, entre outros.

Em face disso, as EEEPs do Ceará adotaram, desde a sua implantação, o modelo de gestão Tecnologia Empresarial Sócio Empresarial (TESE) (CASTELO BRANCO; MAGALHÃES JR., 2015). Sendo este guiado por princípios humanísticos (Protagonismo Juvenil, Formação Continuada, Tecnologia Empresarial e Níveis de Resultados) e direcionado às etapas de planejamento, gerenciamento e avaliação das ações desenvolvidas pelas Escolas Profissionais, 
cujo gestor assume a responsabilidade de garantir a eficiência, eficácia e efetividade dos processos escolares (CEARÁ, 2014).

Outrossim, a estrutura curricular padrão das EEEPs do Ceará é composta de três áreas, perfazendo um total de 5.400 horas/aula ao final dos três anos; sendo essa estrutura passível de adaptação pelas comunidades escolares, em conformidade com à realidade local (CEARÁ, 2014). O Quadro 2 apresenta essa estrutura padrão para todas as EEEPs e ainda exemplifica a adaptação curricular feita pela EEEP RSC, em Juazeiro do Norte.

\section{Quadro 2 - Currículo Padrão das Escolas Profissionais do Ceará e da EEEP RSC}

\section{ESTRUTURA CURRICULAR PADRÃO \\ EEEP RAIMUNDO SARAIVA COELHO}

I. Formação Geral: treze componentes curriculares básicos e comuns ao ensino médio: Língua Portuguesa, Artes, Inglês, Espanhol, Educação Física, História, Geografia, Filosofia, Sociologia, Matemática, Biologia, Física e Química.

II. Formação Profissional: é composta por conteúdos curriculares específicos de cada curso técnico, que obedecem a uma carga horária mínima, de acordo com o Catálogo Nacional dos Cursos Técnicos.

III. Parte Diversificada: os componentes curriculares dessa área são distribuídos entre: Horário de Estudo; Projeto de Vida; Temáticas, Práticas e Vivências; Formação para a Cidadania; Projetos Interdisciplinares e Mundo do Trabalho.

I. Formação Geral Básica: i) Linguagens, Códigos e suas Tecnologias; ii) Matemática e suas Tecnologias; iii) Ciências da Natureza e suas Tecnologias; iv) Ciências Humanas e suas Tecnologias.

II. Formação Profissional: conteúdos curriculares específicos dos cursos técnicos: Agrimensura; Desenho da Construção Civil; Edificações; Design de Interiores; Finanças; Transações Imobiliárias; Meio Ambiente.

III. Parte Diversificada: Estudo Orientado; Formação para a Cidadania; Preparação e avaliação da prática de estágio; Horário de Estudo I e II; Projeto interdisciplinar I e II; Projeto de Vida; Oficina de Redação; Mundo do Trabalho; e Empreendedorismo.

Elaboração: autores. Fonte: CEARÁ (2014; 2019c).

Diante disso, é importante destacar que as atividades teóricas e práticas de EA nas áreas I e II do currículo das EEEPs (ver quadro 2) são fundamentais para a construção de uma "compreensão integrada do meio ambiente em suas múltiplas e complexas relações, envolvendo aspectos ecológicos, psicológicos, legais, políticos, sociais, econômicos, científicos, culturais e éticos" (BRASIL, 1999, art.5ำ § I). Na formação profissional destaca-se a relevância do curso Técnico em Meio Ambiente (ofertado pela EEEP RSC) para a RMC e, especialmente para o município de Juazeiro do Norte, pois entre suas atribuições, estão: minimização dos impactos, recuperação e conservação das áreas degradadas; gestão ambiental; e organização de programas de EA (CEARÁ, 2019c). 
Apesar dessas especificidades, é na Parte Diversificada que à formação dos educandos será acrescida o estudo de determinados temas interdisciplinares (entre eles, a EA) (CEARÁ, 2014). Nessa parte do currículo, a EEEP RSC defende uma maior integração entre a família, escola e comunidade, a fim de mobilizar a formação do discente enquanto cidadão crítico e reflexivo e ajudá-los na construção de uma sociedade mais justa e humana; destacando a responsabilidade social como condição necessária para a conscientização e respeito com as questões sociais e ambientais (CEARÁ, 2019c).

Esse planejamento interdisciplinar resultou na premiação de algumas EEEPs da RMC no "IV Festival Alunos que inspiram", Fase Regional - 2019, organizado pela Seduc e apresentado no Quadro 3. Nos trabalhos foram abordados temas que, direta ou indiretamente, remetem às múltiplas dimensões da EA, tais como: meio ambiente, natureza, biodiversidade, educação, sustentabilidade, territorialidade, etnia, raça e gênero.

Quadro 3 - "IV Festival Alunos que inspiram" - Fase Regional, 2019

\begin{tabular}{|c|c|c|c|}
\hline \multirow{2}{*}{ CATEGORIA } & $\begin{array}{c}\text { EXPRESSÃO } \\
\text { ARTÍsTICA }\end{array}$ & TÍTULO DO TRABALHO & ESCOLA \\
\hline Artes Visuais & Escultura & Árvore na terra da vida & EEEP Otília Correia Saraiva \\
\hline \multirow{2}{*}{ Criação Literária } & Cordel & A diversidade do meio ambiente & EEEP Paulo Barbosa Leite \\
\cline { 2 - 4 } & Crônica & $\begin{array}{c}\text { Educação: a base para a } \\
\text { sustentabilidade }\end{array}$ & $\begin{array}{c}\text { EEEP Raimundo Saraiva } \\
\text { Coelho }\end{array}$ \\
\cline { 2 - 5 } & Dança & Ceará Afrodescendente & $\begin{array}{c}\text { EEEP Aderson Borges de } \\
\text { Carvalho }\end{array}$ \\
\hline Dança & Esquete Teatral & Rainha do cangaço & EEEP Moreira de Sousa \\
\hline Teatro & Curta Metragem & Minha Terra é vermelha & EEEP Raimundo Saraiva \\
& & & Coelho \\
\hline
\end{tabular}

Elaboração: autores. Fonte: CEARÁ (2019d)

No caso específico da EEEP RSC, o seu PPP não cita, explicitamente, atividades teóricas e práticas de EA (CEARÁ, 2019c), porém, nota-se uma constância no uso de algumas palavras (ou termos interdisciplinares) que se conectam às dimensões da sustentabilidade (social, cultural, ambiental, territorial, econômica, política) defendidas por Sachs (2002) e, por 
sua vez, aos princípios da EA apresentados por Brasil (1999; 2012a), como pode ser visto na

Figura 2.

Figura 2 - Temáticas Interdisciplinares à luz da EA na EEEP RSC

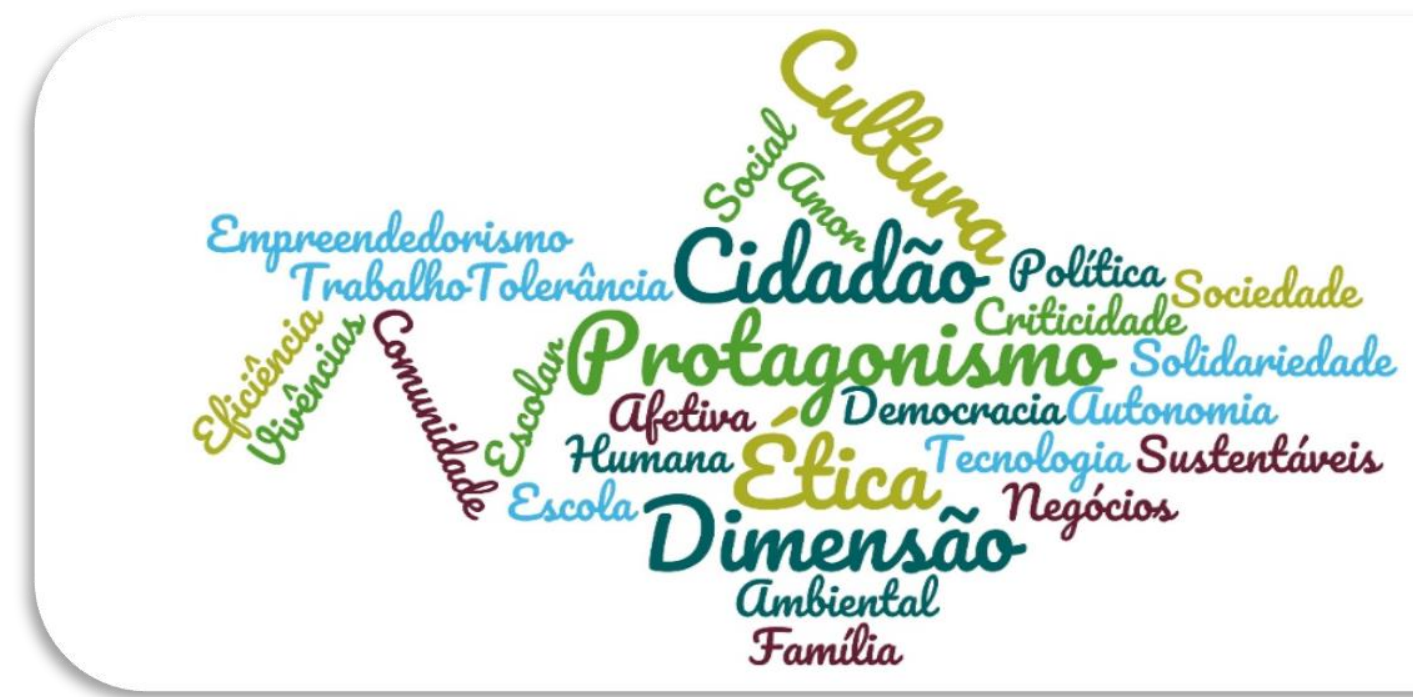

Elaboração: autores. Fonte: CEARÁ (2019c)

No mais, resta saber: como as EEEPs do munícipio de Juazeiro do Norte têm "pensando" acerca das atividades didático-pedagógicas de EA? Qual o perfil institucional da EA na rede estadual de EPT de nível médio no município de Juazeiro do Norte?

\subsection{Ações didático-pedagógicas de EA na EEEP Raimundo Saraiva Coelho}

Na tentativa de verificar o perfil da EA na EPT de nível médio, particularmente das EEEPs do município de Juazeiro do Norte, decidiu-se pelo Estudo de Caso na EEEP RSC. A definição deste perfil de EA embasou-se, inicialmente, através da realização de entrevista (na modalidade por pauta) com a antiga Gestão da referida escola. O Quadro 4 sintetiza a construção das pautas a partir da matriz de indicadores para avaliação de EA em escolas, segundo proposta de Vieira, Campos e Morais (2019).

Não obstante, os resultados da entrevista foram estruturados a partir dos três indicadores (gestão, currículo e espaço físico) e correlacionados as dimensões da sustentabilidade, defendidas por Sachs (2002); classificando como ações de EA não apenas 
aquelas ligadas a conservação do meio ambiente, mas também atividades de cunho socioeconômico, cultural, territorial e político.

\begin{tabular}{|c|c|c|}
\hline DIMENSÃO & INDICADORES & PAUTAS \\
\hline \multirow{4}{*}{ GESTÃO } & 1. Gestão democrática & $\begin{array}{l}\text { Mobilização da comunidade escolar para o fortalecimento da } \\
\text { cidadania e construção coletiva de sociedades sustentáveis. }\end{array}$ \\
\hline & $\begin{array}{l}\text { 2. Instrumentos de } \\
\text { planejamento, gestão } \\
\text { e comunicação }\end{array}$ & $\begin{array}{l}\text { Ações de EA previstas no PPP escolar e no Plano de Trabalho } \\
\text { Docente. }\end{array}$ \\
\hline & 3. Instâncias Colegiadas & Mediação de instâncias colegiadas. \\
\hline & $\begin{array}{l}\text { 4. Suficiência de } \\
\text { recursos humanos e } \\
\text { financeiros }\end{array}$ & $\begin{array}{l}\text { Formação continuada dos docentes em EA e acesso à recursos } \\
\text { financeiros para ações de EA. }\end{array}$ \\
\hline \multirow{3}{*}{ CURRÍCULO } & $\begin{array}{l}\text { 5. Organização } \\
\text { curricular }\end{array}$ & $\begin{array}{l}\text { Tratamento do currículo pedagógico (especificidades dos } \\
\text { cursos e aspectos socioambientais locais). }\end{array}$ \\
\hline & $\begin{array}{l}\text { 6. Atividades práticas e } \\
\text { pedagógicas }\end{array}$ & $\begin{array}{l}\text { Formas de inserção da EA no currículo: transversalidade e/ou } \\
\text { como conteúdo dos componentes curriculares. }\end{array}$ \\
\hline & 7. Projetos e Programas & Ações didático-pedagógicas de EA na comunidade escolar. \\
\hline \multirow{3}{*}{ ESPAÇO FÍSICO } & $\begin{array}{l}\text { 8. Território da escola e } \\
\text { entorno }\end{array}$ & $\begin{array}{l}\text { Adequabilidade da estrutura física para o fomento da EA } \\
\text { (interno e externamente). }\end{array}$ \\
\hline & $\begin{array}{l}\text { 9. Infraestrutura e } \\
\text { ambiente educativo }\end{array}$ & $\begin{array}{l}\text { Ambiente escolar como espaço de participação, } \\
\text { desenvolvimento de práticas pedagógicas e vivências coletivas } \\
\text { de afeto com o ambiente físico. }\end{array}$ \\
\hline & Ecoeficiência & $\begin{array}{l}\text { Estímulo a redução de desperdícios no consumo de materiais; } \\
\text { de energia; e de resíduos que poluem o meio ambiente. }\end{array}$ \\
\hline
\end{tabular}

Elaboração: autores. Fonte: Adaptado de Vieira, Campos e Morais (2019).

No âmbito da Gestão, a escola realiza anualmente a Jornada Pedagógica, com a participação de professores, pais e alunos, para definir, em comum acordo, todas as ações (incluindo a EA) previstas para aquele ano letivo. Além disso, viabiliza a participação de toda a comunidade escolar na construção, cumprimento e atualização do seu PPP. Destaca ainda que são realizadas diversas atividades de caráter socioambiental e cultural na instituição; dentre essas, algumas são apresentadas na Figura 3.

Além disso, a gestão cita ações institucionais que já são previstas pela legislação, como a Comissão de Combate à Dengue e a Comissão de Meio Ambiente e Qualidade de Vida (COM-VIDA); onde são estimuladas ações de EA nas escolas de ensino fundamental e médio, por meio da criação e manutenção de um espaço democrático, congregando na participação de toda a comunidade escolar em ações voltadas para a sustentabilidade socioambiental e qualidade de vida na escola e sua comunidade (BRASIL, 2007b). 
Figura 3 - Ações de EA na EEEP RSC
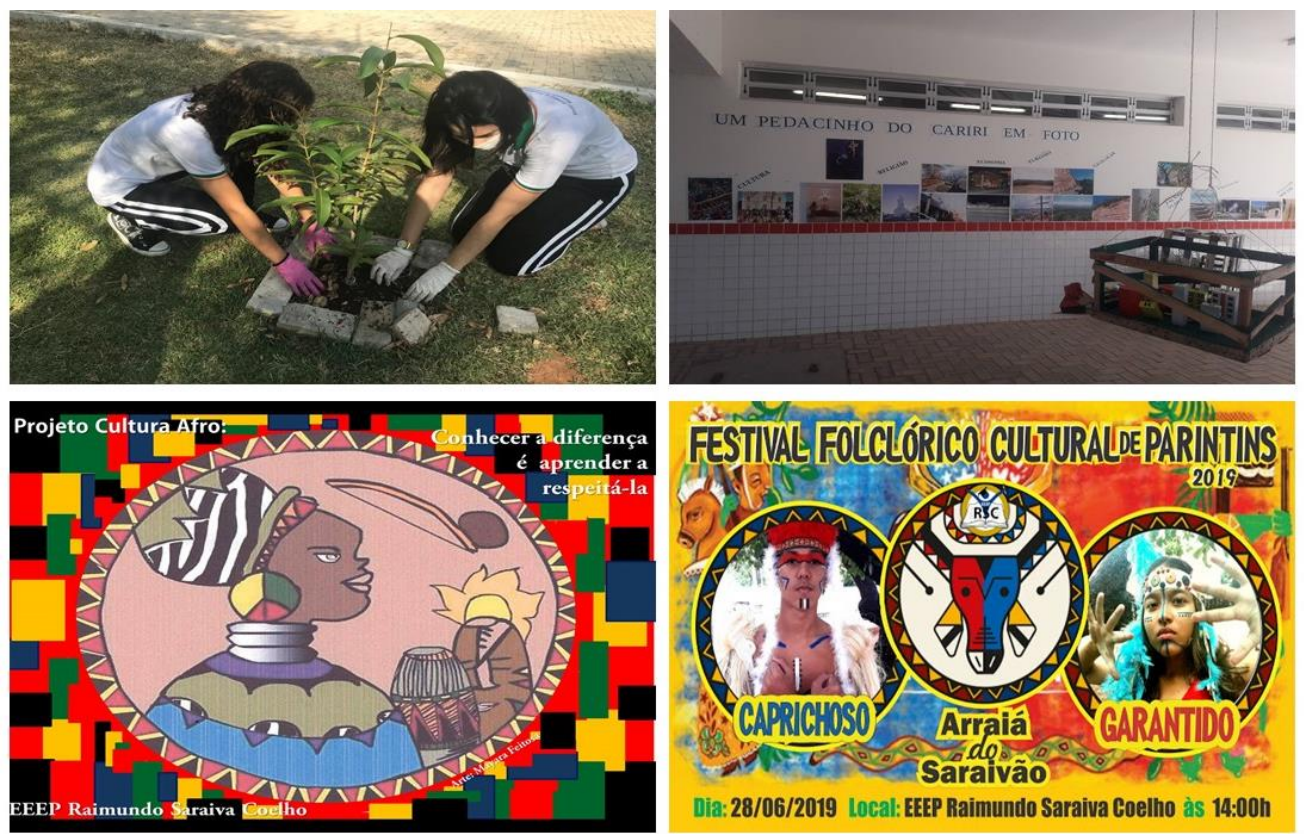

Fonte: CEARÁ (2019b).

Em relação à formação continuada dos docentes em EA, a instituição oferta um curso de formação específica, com certificado e carga horária de 80 horas, autorizado pela Seduc; dividido em módulos, e um deles trata da EA. Essas ações de formação são objeto contínuo de planejamento por parte dos coordenadores pedagógicos, incluindo aquelas atividades ligadas as questões ambientais, tais como a COM-VIDA e a Semana do Meio Ambiente, entre outras. No que concerne aos recursos financeiros, estes já vêm direcionados para a manutenção da escola, como parte elétrica, conservação do prédio, limpeza, material de escritório etc. Portanto, não há um recurso específico direcionado para a EA na escola, a não ser para a escola vencedora do Projeto Escola Selo Sustentável, lançado pela Seduc.

Na dimensão Currículo, ao ser questionada sobre a inserção das ações de EA no PPP da Escola, foi posto que, de maneira geral, todas as disciplinas da Formação Geral e da Formação Profissional contemplam ações interdisciplinares de EA, mas é na Parte Diversificada do currículo (vide quadro 2), tais como Empreendedorismo, Formação para a Cidadania, Projetos Interdisciplinares, Horário de Estudo e Mundo do Trabalho que são desenvolvidas ações de EA. Além disso, no Curso Técnico de Meio Ambiente, tanto a EA quanto Meio Ambiente são trabalhados como disciplinas específicas. 
Apesar disso, a gestão reconhece a dificuldade para inserção das temáticas voltadas para a EA em todas as disciplinas, especialmente nas áreas de química, biologia e ciências da natureza. Isso ocorre, na opinião de Trajber (2017) porque no Brasil as legislações no âmbito da educação apenas citam a temática como o sentido científico, biológico e/ou ecológico, com palavras como "paisagem", "conhecimento ambiental-ecológico", "meio ambiente" e "fenômenos naturais".

Sobre a inserção da realidade socioeconômica e cultural do discente no ambiente escolar, a Gestão reitera que, apesar de existir uma cobrança maior na escola profissional pela aprendizagem curricular, "nós sempre procuramos inserir o contexto do aluno, trazer para a escola todas essas temáticas sociais, para que aluno não aprendesse unicamente aquela educação livresca, conteudista, mas que tivesse essa formação para a vida, essa inserção na sociedade e no mercado de trabalho"6. Nesta perspectiva, são apresentados na sequência os principais projetos e ações de EA vivenciados pela EEEP RSC (Quadro 5); estes foram citados durante a entrevista com a Gestão e/ou obtidos no blog da escola.

Além desses, objetivando alcançar a meta estabelecida pelo Governo do Estado do Ceará de reduzir até $20 \%$ no consumo de energia elétrica e de água, a escola passou a desenvolver algumas ações, como: ligar os aparelhos de ar condicionado somente a partir das 8 horas; desligar lâmpadas e ar condicionados nos ambientes sem funcionamento; redução na frequência do uso do auditório; conserto dos vazamentos em torneiras, canos e bebedouros. São incentivados ainda o reaproveitamento de papel, o não uso de material descartável; estímulo a redução na produção de lixo, resíduos e de desperdício de alimentos.

No tocante a dimensão Espaço Físico, a Gestão enfatiza a boa estrutura física (acústica e térmica) da escola e adequação dos ambientes para realização das atividades diversas. Comenta que o terreno doado em parceria com o município de Juazeiro do Norte para a construção da EEEP RSC é bem amplo e propício para realização de aulas de campo, plantio de árvores, atividades artísticas e culturais, entre outras.

6 Na seção 4.2, as citações diretas grafadas em itálico representam a fala da Gestão da EEEP RSC. 
Quadro 5 - Ações teóricas e práticas de EA na EEEP RSC

\begin{tabular}{|c|c|c|}
\hline & $\begin{array}{l}\text { TIPO DE } \\
\text { PRÁTICA }\end{array}$ & DESCRIÇÃO \\
\hline 1 & $\begin{array}{l}\text { Alunos } \\
\text { Protagonistas }\end{array}$ & $\begin{array}{l}\text { São selecionados para atuar no contexto social onde estão inseridos. Colaborando com } \\
\text { a limpeza e conservação de toda a escola. "São uma espécie de agente ambiental". }\end{array}$ \\
\hline 2 & $\begin{array}{l}\text { Feira de } \\
\text { Ciências }\end{array}$ & $\begin{array}{l}\text { VII Feira de Ciências e Cultura RSC - "Com respeito à diversidade, cultivamos amor, } \\
\text { empreendedorismo e sustentabilidade" objetiva incentivar os trabalhos científicos e } \\
\text { culturais no âmbito da escola. } \\
\text { Áreas para inscrição dos Projetos: linguagens, ciências humanas, ciências da natureza } \\
\text { e engenharia, educação ambiental, matemática, apresentação artística e robótica. }\end{array}$ \\
\hline 3 & Fórum de EA & Espaço virtual para debate das ações de EA na escola. \\
\hline 4 & Palestras & $\begin{array}{l}\text { Sobre consumo consciente; alusiva ao dia mundial da água; sobre a responsabilidade } \\
\text { na redução da poluição e nos danos ambientais. }\end{array}$ \\
\hline 5 & $\begin{array}{l}\text { Projeto de } \\
\text { Educação } \\
\text { Ambiental }\end{array}$ & $\begin{array}{l}\text { Realização de ações de EA no curso técnico de Meio Ambiente, em parceria com o } \\
\text { Curso de Engenharia Ambiental, do Instituto Federal do Ceará (IFCE). }\end{array}$ \\
\hline 6 & $\begin{array}{l}\text { Projeto } \\
\text { Escola Verde }\end{array}$ & $\begin{array}{l}\text { Os alunos realizam trilhas dentro da Escola e são responsáveis pela plantação e } \\
\text { cuidado com as árvores; adaptando espaços com materiais recicláveis, como a } \\
\text { construção de bancos e pinturas diversas. }\end{array}$ \\
\hline 7 & $\begin{array}{l}\text { Projeto de } \\
\text { Logística } \\
\text { Reversa }\end{array}$ & $\begin{array}{l}\text { É desenvolvido pelo Curso de Meio Ambiente, com o objetivo de coletar produtos } \\
\text { eletrônicos: baterias, pilhas, carregadores, teclados etc.; e assim, possibilitar a } \\
\text { destinação adequada desses resíduos. }\end{array}$ \\
\hline 8 & $\begin{array}{l}\text { Projeto } \\
\text { Recicla Pet }\end{array}$ & São realizadas ações de coleta e reciclagem de garrafas pet. \\
\hline 9 & Oficinas & $\begin{array}{l}\text { Realizadas nas disciplinas de Empreendedorismo e Mundo do Trabalho. Com foco na } \\
\text { sustentabilidade, visa a criação de produtos com materiais recicláveis. }\end{array}$ \\
\hline 10 & $\begin{array}{l}\text { Semana do } \\
\text { Meio } \\
\text { Ambiente }\end{array}$ & $\begin{array}{l}\text { Tema: } 5 \text { Rs e a promoção do desenvolvimento sustentável: "o ato de conservar está } \\
\text { em cada um de nós". }\end{array}$ \\
\hline
\end{tabular}

Elaboração: autores. Fonte: CEARÁ (2019b).

Por último, a gestão reconhece a facilidade de acesso aos documentos, legislações, materiais informativos e pedagógicos de EA. Aponta que o maior desafio para a disseminação das ações de EA é ainda a permanência de uma educação tradicional, de caráter conteudista. Onde finaliza, "essa educação mais aberta, mais livre, mais pessoal, de trabalhar uma educação para a vida ainda é de certa forma meio escanteada".

\section{CONSIDERAÇÕES FINAIS}

Neste trabalho as análises realizadas à luz das ações teóricas e práticas de EA no ensino médio profissional de Juazeiro do Norte, Ceará, evidenciaram que a escola, objeto de estudo 
de caso dessa pesquisa, vêm desenvolvendo um conjunto de ações didático-pedagógicas de EA em conformidade com as diretrizes nacional, estadual e municipal para inserção interdisciplinar dessas atividades na EPT de nível médio.

Em virtude da obrigatoriedade da inserção transversal da EA em todas as modalidades e níveis de ensino no país, bem como do modelo padrão de gestão que regimenta a atuação das Escolas Profissionais do Ceará, pode-se inferir que essas ações didático-pedagógicas também são vivenciadas pelas demais EEEPs do município em questão, cada qual nas suas particularidades locais; onde apresentam um perfil institucional de EA em consonância com as dimensões da sustentabilidade de Sachs (2002).

Este perfil institucional de EA conflui para uma gestão democrática, incentivo do protagonismo juvenil e cidadania dos discentes que ali ingressam; valorização sociocultural e ambiental dos territórios no qual os cursos técnicos estão inseridos; formação e capacitação para o mercado de trabalho e, com isso, uma possibilidade de mudança na realidade socioeconômica dos discentes e de suas famílias.

Entretanto, a fim de estimular uma maior disseminação dessas ações no ambiente escolar das EEEPs, reitera-se a necessidade de superação da educação tradicional e da ênfase dos órgãos superiores da EPT na aprendizagem curricular, em detrimento de uma formação para a vida. Porquanto, citam-se como possibilidades de pesquisas futuras: i) o debate em torno da educação tradicional e seus efeitos sobre as ações de EA; e, ii) os impactos da atualização da Base Nacional Comum Curricular (BNCC) sobre a continuidade das ações de EA no país.

\section{AGRADECIMENTOS}

Agradecemos o apoio concedido pela EEEP Raimundo Saraiva Coelho ao nosso trabalho, especialmente quanto à disponibilidade de acesso da autora principal às instalações da instituição (antes da pandemia do COVID-19) e aos documentos institucionais.

Os autores agradecem ainda a colaboração e participação da gestão anterior da EEEP RSC pelas entrevistas concedidas. Estamos certos de que suas informações foram fundamentais para o enriquecimento e conclusão satisfatória deste trabalho.

O presente trabalho foi realizado com apoio da Coordenação de Aperfeiçoamento de Pessoal de Nível Superior - Brasil (CAPES). 


\section{REFERÊNCIAS}

AGUIAR NETO, Raimundo Pereira; TEIXEIRA, Michele da Silva. Desenvolvimento Regional: um estudo na região metropolitana do cariri. Id on line Revista de Psicologia, Pernambuco, v.1, n.18, p. 13-32, nov. 2012.

BARRETO, Polliana Luna N.; CHACON; Suely Salgueiro; NASCIMENTO, Verônica Salgueiro do. Educação e desenvolvimento sustentável: a expansão do ensino superior na região metropolitana do Cariri. Sustentabilidade em Debate, Brasília, v. 3, n. 1, p. 117-134, jan./jun. 2012.

BRASIL. Decreto no 6.302, de 12 de dezembro de 2007. Institui o Programa Brasil Profissionalizado. Brasília, DF: Presidência da República, [2007a]. Disponível em: http://www.planalto.gov.br/ccivil_03/_Ato2007-2010/2007/Decreto/D6302.htm. Acesso em: 5 maio. 2020.

BRASIL. Lei no 9.795, de 27 de abril de 1999. Dispõe sobre a educação ambiental, institui a Política Nacional de Educação Ambiental e dá outras providências. Brasília, DF: Presidência da República, [1999]. Disponível em: http://www.planalto.gov.br/ccivil_03/leis/19795.htm. Acesso em: 15 abr. 2020.

BRASIL. Ministério da Educação. Secretaria de Educação Continuada, Alfabetização e Diversidade. Formando Com-vida, Comissão de Meio Ambiente e Qualidade de Vida na Escola: construindo Agenda 21 na escola. 2. ed., rev. e ampl. - Brasília: MEC, Coordenação Geral de Educação Ambiental, [2007b].

BRASIL. Ministério da Educação. Sistema Integrado de Monitoramento Execução e Controle - SIMEC. Painel Obras: construção da EEEP de Farias Brito. [2020a]. Disponível em: http://simec.mec.gov.br/painelObras/dadosobra.php?obra=1023772. Acesso em 15 abr. 2020.

BRASIL. Ministério da Educação. Sistema Integrado de Monitoramento Execução e Controle - SIMEC. Painel Obras: construção da EEEP de Missão Velha. [2020b]. Disponível em: http://simec.mec.gov.br/painelObras/dadosobra.php?obra=1023783. Acesso em 15 abr. 2020.

BRASIL. Ministério da Educação. Sistema Nacional de Informações da Educação Profissional e Tecnológica - SisTec. Consulta pública das Escolas e Cursos Técnicos Regulares nos Sistemas de Ensino e Cadastradas no MEC. [2020c]. Disponível em: https://sistec.mec.gov.br/consultapublicaunidadeensino/\#. Acesso em 17 abr. 2020.

BRASIL. Ministério do Meio Ambiente. Educação ambiental por um Brasil sustentável: ProNEA, marcos legais e normativos [recurso eletrônico]. Brasília, DF: MMA, [2018a]. Disponível em: https://antigo.mma.gov.br/images/arquivo/80219/Pronea_final_2.pdf. Acesso em: 20 abr. 2020. 
BRASIL. Resolução no 2, de 15 de junho de 2012. Estabelece as Diretrizes Curriculares Nacionais para a Educação Ambiental. Brasília, DF: Ministério da Educação, [2012a]. Disponível em: http://portal.mec.gov.br/dmdocuments/rcp002_12.pdf. Acesso em: 10 mai. 2020.

BRASIL. Resolução no 3, 21 de novembro de 2018. Atualiza as Diretrizes Curriculares Nacionais para o Ensino Médio. Brasília, DF: Ministério da Educação, [2018b]. Disponível em: http://novoensinomedio.mec.gov.br/resources/downloads/pdf/dcnem.pdf. Acesso em: 20 mai. 2020.

BRASIL. Resolução no 6, de 20 de setembro de 2012. Define as Diretrizes Curriculares Nacionais para a Educação Profissional Técnica de Nível Médio. Brasília, DF: Ministério da Educação, [2012b]. Disponível em:

http://portal.mec.gov.br/index.php?option=com_docman\&view=download\&alias=11663rceb006-12-pdf\&category_slug=setembro-2012-pdf\&Itemid=30192. Acesso em: 6 jun. 2020.

BRASIL. Resolução no 510, de 07 de abril de 2016. Dispõe sobre as normas aplicáveis a pesquisas em Ciências Humanas e Sociais [...]. Brasília, DF: Conselho Nacional de Saúde, [2016]. Disponível em:

https://bvsms.saude.gov.br/bvs/saudelegis/cns/2016/res0510_07_04_2016.html. Acesso em: 25 mai. 2020.

CASTELO BRANCO, Caroline Silva; MAGALHÃES JR., Antônio Germano. Política de Ensino Profissionalizante do Governo do Estado do Ceará (2008-2013). Conhecer: debate entre o público e o privado. n. 13, 2015.

CASTRO, Marília de Sousa; OLIVEIRA, Aline Alves de; PEREIRA, William Eufrásio Nunes. Panorama e dinâmica recente da economia da Região Metropolitana do Cariri (RMC). Revista de Economia Regional, Urbana e do Trabalho, v. 2, n.1, p. 47-58. 2013.

CEARÁ. Decreto estadual no 33.510, de 16 de março de 2020. Decreta situação de emergência em saúde e dispõe sobre medidas para enfrentamento e contenção da infecção humana pelo novo Coronavírus. Ceará: Governo do Estado, [2020a].

CEARÁ. Governo do Estado do Ceará. Secretaria de Educação. Educação Profissional. [2019a]. Disponível em: https://educacaoprofissional.seduc.ce.gov.br. Acesso em: 09 abr. 2019.

CEARÁ. EEEP Raimundo Saraiva Coelho. [2019b]. Blog. Disponível em: http://rscoelho2011.blogspot.com/. Acesso em 05 ago. 2020.

CEARÁ. EEEP Raimundo Saraiva Coelho. Projeto Político Pedagógico. [2019c]. 
CEARÁ. Lei no 14.273, de 19 de dezembro de 2008. Dispõe sobre a criação das Escolas Estaduais de Educação Profissional - EEEP. Ceará, Governo do Estado: Secretaria de Educação. [2008]. Disponível em: https://apeoc.org.br/wpcontent/uploads/2010/11/LEI.n.14273de2008.pdf. Acesso em: 5 maio. 2020.

CEARÁ. Lei no 14.892, de 31 de março de 2011. Dispõe sobre a educação ambiental, institui a política estadual de educação ambiental e dá outras providências. Ceará, Governo do Estado: Secretaria de Educação. [2011]. Disponível em: http://imagens.seplag.ce.gov.br/PDF/20110404/do20110404p01.pdf. Acesso em: 30 abr. 2020.

CEARÁ. Relatório de gestão "O pensar e o fazer da educação profissional no Ceará - 2008 a 2014". Ceará, Fortaleza: Secretaria da Educação, 2014.

CEARÁ. Resultado final da seleção de alunos 2020 para as EEEPs de Barbalha, Caririaçu, Jardim e Juazeiro do Norte. Ceará, Secretaria da Educação: Coordenadoria Regional de Educação (CREDE 19), [2020b]. Disponível em:

https://crede19.seduc.ce.gov.br/index.php/listanoticias/3131-resultado-final-da-selecao-dealunos-2020-para-as-eeep. Acesso em: 25 abr. 2020.

CEARÁ. Resultado final da seleção de alunos 2020 para as EEEPs de Crato e Nova Olinda. Ceará, Secretaria da Educação: Coordenadoria Regional de Educação (CREDE 18), [2020c]. Disponível em: https://crede18.seduc.ce.gov.br/index.php/listanoticias. Acesso em: 25 abr. 2020.

CEARÁ. Resultado final do IV Festival Alunos que inspiram/Fase Regional. Ceará, Secretaria da Educação: Coordenadoria Regional de Educação (CREDE 19), [2019d]. Disponível em: https://crede19.seduc.ce.gov.br/images/RESULTADOS_DA_FASE_REGIONAL_DO_IV_FESTIV AL_ALUNOS_QUE_INSPIRAM.pdf. Acesso em 12 maio. 2020.

CMMAD, Comissão Mundial Sobre Meio Ambiente e Desenvolvimento. Nosso Futuro Comum. 2a ed. Rio de Janeiro: Editora da Fundação Getúlio Vargas, 1991.

GIL, Antonio Carlos. Métodos e técnicas de pesquisa social. 6 ed. São Paulo: Atlas, 2008.

IBGE. Instituto Brasileiro de Geografia e Estatística. Panorama da cidade de Juazeiro do Norte. [2020]. Disponível em: https://cidades.ibge.gov.br/brasil/ce/juazeiro-donorte/panorama. Acesso em: 20 abr. 2020.

IPECE. Instituto de Pesquisa e Estratégia Econômica do Ceará. Ceará em mapas. Fortaleza: IPECE, 2019. Disponível em:

http://www2.ipece.ce.gov.br/atlas/georreferenciados/index.htm Acesso em 06 mai. 2020. 
IPECE. Panorama socioeconômico das regiões metropolitanas cearenses. Fortaleza: IPECE: 2018.

JUAZEIRO DO NORTE. Lei $\mathbf{n}$ - 3851, 17 de agosto de 2011. Estabelece a Política Municipal do Meio Ambiente e dá outras providências. Ceará: Juazeiro do Norte. [2011]. Disponível em: https://www.juazeirodonorte.ce.gov.br/site/midia/9158/LEl\%20N\%C2\%B0\%203851-2011ESTABELECE\%20A\%20POLITICA\%20MUNICIPAL\%20DO\%20MEIO\%20AMBIENTE.pdf. Acesso em: 15 maio. 2020.

LEITE, Maria Cleide da Silva Ribeiro; ANDRADE, Francisca Rejane Bezerra. Ensino médio, educação profissional e Programa Brasil Profissionalizado: análises e tensões pós lei 9394/1996. Revista Multidisciplinar de Ensino, Pesquisa, Extensão e Cultura do Instituto de Aplicação Fernando Rodrigues da Silveira (CAp-UERJ). v. 8, n. 19, set./dez. 2019.

MORAIS, José Micaelson Lacerda; MACEDO, Fernando Cezar de. Regiões Metropolitanas do Ceará: dispersão produtiva e concentração de serviços. DRd - Desenvolvimento Regional em debate. v. 4, n. 2, p. 178-203, jul./dez. 2014.

NASCIMENTO, Diego Coelho do; ROCHA, Gledson Alves; COSTA, Celme Torres Ferreira da; CHACON, Suely Salgueiro. Planejamento Estratégico e Desenvolvimento Regional Sustentável: análise da necessidade de mecanismos de gestão na Região Metropolitana do Cariri - Ceará. Revista NAU Social, v. 3, n. 5, p. 107-119, nov./abr. 2013.

SACHS, Ignacy. Caminhos para o desenvolvimento sustentável. Rio de Janeiro: Garamond, 2002.

SACHS, Ignacy. Desenvolvimento: includente, sustentável, sustentado. Rio de Janeiro: Garamond, 2008.

TRAJBER, Raquel. Educação ambiental, mudanças climáticas e prevenção de desastres: por políticas públicas emergentes e emergenciais. In: GUERRA, Antonio Fernando Silveira; FIGUEIREDO, Maria Lúcia (Org). Diálogos de Saberes e Fazeres: uma releitura dos 25 anos da trajetória da educação ambiental brasileira. São José: ICEP, 2017. E-book (490p.). Disponível em: https://drive.google.com/file/d/1JPwIPO6e6I6uhEgqS81LKEYXNDJOMCE2/view. Acesso em: 20 abr. 2020.

VIANA, Cláudia Ferreira de Maya; CASTIONI, Remi. Programa Brasil Profissionalizado: coordenação federativa, formulação e implementação da política nacional de expansão das redes estaduais de educação profissional. Perspectivas em Políticas Públicas, Belo Horizonte, v. 10, n. 19, p. 129-163, jan./jun. 2017.

VIEIRA, Solange Reiguel; CAMPOS, Marilia Andrade Torales; MORAIS, Josmaria Lopes. Indicadores de Avaliação de Educação Ambiental em escolas. In: RAYMUNDO, Maria Henriqueta Andrade et al. (Orgs). Avaliação e monitoramento de políticas públicas de educação ambiental no Brasil: transição para sociedades sustentáveis. Piracicaba: $\mathrm{MH}-$ Ambiente Natural, 2019. ISBN: 978-85-54939-03-8. 
YIN, Robert K. Estudo de caso: planejamento e métodos. Tradução: Daniel Grassi. 2.ed. Porto Alegre: Bookman, 2001.

Submetido em: 26-08-2020.

Publicado em: 23-04-2021. 